\title{
Past4Future: European interdisciplinary research on past warm climate periods
}

\author{
Dorthe Dahl-Jensen', E. Capron², P. Vallelonga ${ }^{3}$ and D.M. Roche ${ }^{4,5}$
}

\begin{abstract}
Past4Future was a Collaborative Project in the European Union's Framework

Programme 7; it aimed to generate knowledge about climate changes during the last two interglacials. The approach was to combine proxy data with climate model simulations to investigate the existence and the cause of past abrupt climate changes during warm climate periods in order to evaluate the risk of abrupt changes in the future. Featuring contributions from a number of Past4Future participants, this Science Highlights section of PAGES Magazine showcases the cross-disciplinary nature of this very successful project that ended in December 2014.
\end{abstract}

One focus was to define the climatic and environmental conditions during the last two interglacials. A compilation of temperature changes in the high latitudes evidenced that the onset of the Last Interglacial warming occurred first in the Southern Hemisphere but was stronger in the Northern Hemisphere (Capron et al. p. 4). In addition, new paleoclimatic records covering the last two interglacials and their preceding deglaciations have unveiled abrupt environmental and climatic changes in sea ice extent (Sha et al. p. 24), oceanic circulation (Galaasen et al. p. 20; Marino and Zahn p. 22), sea surface salinity (Rodriguez-Sanz and Mortyn p. 6), and sea surface temperature (Martrat et al. p. 10). Abrupt changes in benthic foraminiferal $\delta^{13} \mathrm{C}$ at the onsets of the last two interglacials (Galaasen et al. p. 20) combined with direct simulations of $\delta^{13} \mathrm{C}$ (Bakker et al. p. 18) sug gest that abrupt climate changes are likely to be related to reductions in North Atlantic Deep Water formation. Modeling experiments including freshwater and volcanic forcing (Roche et al. p. 8) further constrain that the risk of future changes at the centennial scale is related to the stability of the Atlantic Meridional Ocean Circulation, and that volcanic eruptions are unlikely to cause strong climate changes of longer duration than a decade.

Another objective of Past4Future was to better understand global biogeochemical feedbacks between climate and the carbon and nitrogen cycles during interglacials. Antarctic ice core measurements of past $\mathrm{CO}_{2}$ concentration and its isotopic composition, provide new evidence that the rise of $\mathrm{CO}_{2}$ concentrations over the mid-Holocene cannot be man-made, but could be related to long-term re-equilibration of carbonate chemistry in the ocean (Fisher et al. p. 12). Biomass burning is also an important process affecting both regional and global climate, through the emission of greenhouse gases and particulates that reflect and absorb incoming solar radiation. New past fire activity tracers measured in ice cores were developed (Kerwhald et al. p. 14) and techniques to better compare biomass burning model simulations with the available datasets were established (Brücher et al. p. 16).

Overall, the Past4Future findings unambiguously demonstrate that abrupt climate changes are not limited to glacial conditions, but can also occur in a warm world. Changing ocean circulation, increasing greenhouse gas concentrations and instabilities of the remaining polar ice sheets are candidates for causing future abrupt changes.

The strength of the project relied on the interdisciplinary team of experts, which brought together the paleoclimatic data and modeling communities. While the research was centered on paleoclimate conditions and can therefore be classified as fundamental research, the knowledge gained is relevant for predictions - especially those relating to the risk and time scales connected to abrupt climatic and environmental changes in the near and more distant future.

A strong emphasis was also put on communicating the project results to an audience including scientists within and external to the climate science community, as well as policymakers, and the public (Dahl-Jensen p. 26).

While this five-year project has just ended, it will be crucial to pursue the integrative

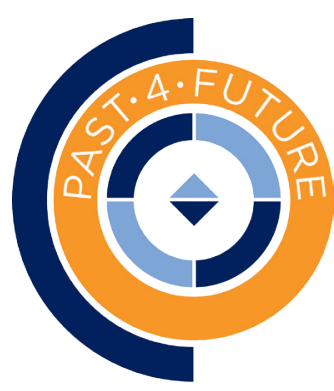

approach it fostered in order to gain additional insights on the causes of past abrupt changes and the potential risk of future ones. Essential future research directions include for example improving (i) paleoclimatic record timescales, (ii) direct modeling of paleoclimatic tracers, and (iii) data assimilation techniques.

In the future, it is not so clear how programs such as Past4Future may continue under the present European research framework, Horizon2020, where more focus is put on ap plied research and transferable knowledge to the private sector. Under the European Research Council's funding scheme for excellence, PI-driven research projects will thrive, and it is obvious we should encourage scientists to look this way. However, instruments to drive collaborative and integrative science, the backbone of the Past4Future project, may be lacking.

Science does, however, crucially depend on such instruments to coordinate research, synthesize results, and foster the proliferation of scientific knowledge; therefore, providing a base to build our applicable scientific knowledge on issues such as the likelihood of abrupt changes in the future and predicting the associated risks.

\section{ACKNOWLEDGEMENTS}

The research leading to these results has received funding from the European Union's Seventh Framework programme (FP7/2007-2013) under grant agreement no. 243908, "Past4Future. Climate change - Learning from the past climate".

\section{AFFILIATIONS}

${ }^{1} \mathrm{C}$ entre for Ice and Climate, Niels Bohr Institute,

University of Copenhagen, Denmark; Coordinator of Past4Future.

2British Antarctic Survey, Cambridge, UK

${ }^{3}$ Centre for Ice and Climate, Niels Bohr Institute, University of Copenhagen, Denmark

Department of Earth Sciences, VU University of Amsterdam, The Netherlands

${ }^{5}$ Laboratoire des Sciences du Climat et de l'Environnement (LSCE), Gif-sur-Yvette Cedex, France

\section{CONTACT}

Dorthe Dahl-Jensen: ddj@nbi.ku.dk

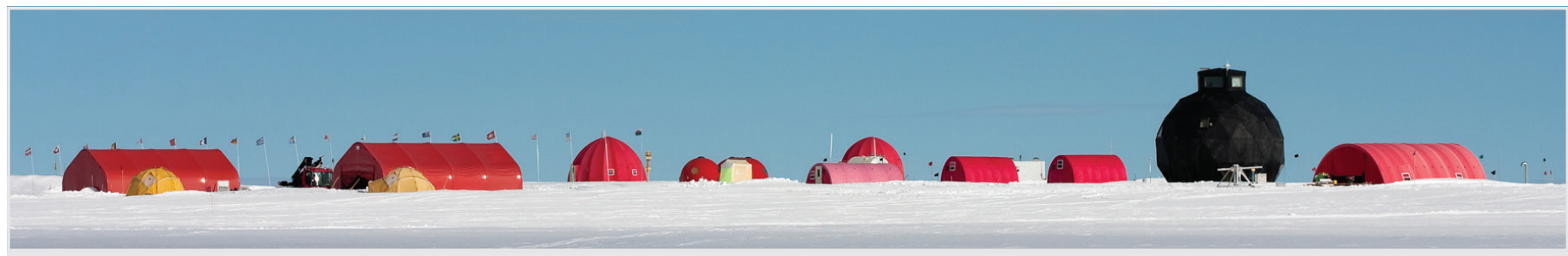

Photo: The camp of the North Greenland Eemian Ice Drilling (NEEM) project where the first complete record of Eemian ice was recovered for Greenland. Photo: T. Burton. 